\title{
Prospective study on the effect of smoking and nicotine substitution on leucocyte blood counts and relation between blood leucocytes and lung function
}

\author{
Erik Juel Jensen, Bente Pedersen, Ruben Frederiksen, Ronald Dahl
}

\begin{abstract}
Background-The influence of smoking and of nicotine substitution on the counts of total blood leucocytes and leucocyte subsets and the relations between the counts and lung function was investigated. Methods-The study was a combined cross sectional and prospective study of 298 smokers and 136 non-smokers. Forced expiratory volume in one second $\left(\mathrm{FEV}_{1}\right)$ was measured in all participants at baseline and six months after quitting smoking in 160 ex-smokers (quitters) and 138 persons with smoking relapse. Blood samples were obtained from all participants at baseline and from 160 quitters and 30 continuing smokers two, six, 12, and 26 weeks after smoking cessation and from 92 quitters one year after the cessation of smoking.
\end{abstract}

Results-Blood leucocyte counts and leucocyte subsets were all higher in smokers than in non-smokers. In cigarette smokers total leucocyte, neutrophil, and lymphocyte blood counts showed a dose dependent relationship with the daily cigarette consumption and pack years consumption. In smokers the neutrophil blood count was independently associated negatively with $\mathrm{FEV}_{1}$ residuals. After quitting smoking total leucocyte, neutrophil, and lymphocyte blood counts decreased during the first 26 weeks and after one year lymphocyte blood counts were higher than in non-smokers. In quitters substituted with nicotine chewing gum (2 $\mathrm{mg}$ ) the accumulated number of pieces of chewing gum used in the 12 weeks had an inverse relationship with the decrease in the total lymphocyte blood count at 12 weeks after smoking cessation.

Conclusions-Leucocyte blood counts are raised in smokers and decrease after smoking cessation. Neutrophil blood counts had an inverse relationship with lung function and nicotine may increase lymphocyte blood counts in smokers. (Thorax 1998;53:784-789)

Keywords: leucocyte blood counts; smoking; lung function; nicotine

Smoking is associated with increased annual loss of lung function ${ }^{12}$ and is the major cause of chronic bronchitis ${ }^{3}$ and emphysema. ${ }^{4}$ A few smokers develop severe lung function impairment. ${ }^{5}$ The reasons for different susceptibility is not known.

Numerous studies ${ }^{6-17}{ }^{18-20}$ have found increased leucocyte blood counts in smokers compared with non-smokers and some studies additionally have found a negative relationship between leucocyte blood counts and lung function in smokers ${ }^{16-20}$ and in non-smokers. ${ }^{18-20}$ Only one study quantified the independent impact on lung function of the total leucocyte blood counts ${ }^{18}$ and none have related neutrophil, lymphocyte, and basophil blood counts to lung function in smokers.

Smoking influences the total number of lymphocytes and the relative distribution of the different lymphocyte subtypes, ${ }^{21-25}$ and smoking may impair lymphocyte function. ${ }^{26}$ The relation of lymphocyte numbers to lung function and the immediate changes in lymphocyte numbers after the cessation of smoking has not been explored. There has been disagreement about the influence of smoking on basophil blood counts. ${ }^{27-29}$

Large cross sectional studies ${ }^{10}{ }^{12}$ have found a persistent increase of, in particular, neutrophil blood counts in ex-smokers, but changes after smoking cessation have never been investigated in a prospective study.

Chronic bronchitis and episodes of acute airway inflammation in smokers relative to non-smokers, ${ }^{16} 1930$ stimulation of lung macrophages to produce neutrophil chemotactic factors, and enhancement of neutrophil chemotactic responsiveness ${ }^{31} 32$ have been proposed as responsible factors for the increased leucocyte counts in smokers. Plasma nicotine levels correlate directly with the leucocyte blood counts in smokers ${ }^{33}$ but a direct stimulation of the bone marrow by tobacco smoke has not been shown.

The purposes of this study were to compare blood counts of total leucocytes and leucocyte subsets between smokers and non-smokers cross sectionally and to follow leucocyte blood counts prospectively immediately after cessation of smoking. We also wanted to explore the relationship between blood total leucocyte and leucocyte subsets and lung function before and after smoking cessation. Finally, we wanted to investigate whether substitution with nicotine chewing gum in ex-smokers influences leucocyte blood counts. 
Table 1 Demographic details and total leucocyte, neutrophil, lymphocyte, and basophil blood counts per $\mu l$ at baseline for smokers and non-smokers

\begin{tabular}{lll}
\hline & Smokers & Non-smokers \\
\hline No. & 298 & 136 \\
Age (years) & $43.5(12.2)$ & $45(13.1)$ \\
M/F & $146 / 153$ & $65 / 72$ \\
Industrial/office workers & $99 / 199$ & $56 / 80$ \\
Smoking duration (years) & $22.6(7.5)$ & - \\
Daily tobacco consumption† (cigarettes per day) & $21.9(8.5)$ & - \\
Pack years consumption $\dagger$ & $25.4(14.4)$ & - \\
No. of cigarette smokers & 237 & - \\
Total blood leucocytes & $7.6(7.4$ to 7.9$)$ & $5.8(5.6 \text { to } 6.0)^{\star}$ \\
Total blood neutrophils & $4.5(4.3$ to 4.7$)$ & $3.2(3.0 \text { to } 3.4)^{\star}$ \\
Total blood lymphocytes & $2.4(2.3$ to 2.5$)$ & $2.0(1.9$ to 2.2$)$ \\
Total blood basophils & $0.02(0.01$ to 0.03$)$ & $0.01(0.00 \text { to } 0.02)^{\star \star}$
\end{tabular}

Values are mean (SD) for demographic variables and mean (95\% CI) for leucocyte blood counts. ${ }^{\star} \mathrm{p}<0.0001 ;{ }^{\star \star} \mathrm{p}<0.01$, non-parametric test.

†See the text for definition.

Table 2 Mean (SD) demographic variables for 160 ex-smokers (quitters) and 30 continuing smokers

\begin{tabular}{llll}
\hline & Quitters $(n=160)$ & Cont. smokers $(n=30)$ & $p$ \\
\hline Age (years) & $43(13)$ & $43(11)$ & NS \\
Sex (M/F) & $77 / 83$ & $17 / 13$ & NS \\
Smoking duration (years) & $21.6(11.1)$ & $23.1(9.6)$ & NS \\
Pack years consumptiont & $25.4(18.5)$ & $28.1(17.6)$ & NS \\
Daily cigarette consumption $\dagger$ & $22.7(11.1)$ & $24.1(12.2)$ & NS \\
\hline
\end{tabular}

†See text for definitions.

\section{Methods}

Four hundred and ninety eight Caucasian smokers volunteered to participate in a smoking cessation programme and were followed for one year. Of these, 342 were recruited through the press and the non-smoking control group $(n=163)$ was recruited from local industrial plants and offices.

In the study were included 298 smokers and 136 never smokers who had no history or clinical evidence of asthma or infectious disease within the last 14 days and had reproducible lung function tests. Their demographic data are presented in table 1 which shows that the groups were comparable for all indices.

Blood was collected at the start of the study from all subjects and at two, six, 12, and 26 weeks after smoking cessation from 160 ex-smokers who still were abstinent after six months (quitters) and 30 smokers who never ceased smoking (continuing smokers). Ninety two quitters gave blood samples after one year. Blood samples were obtained at different time points of the day, but each participant gave blood at the same time of the day and after two hours of rest. Continuing smokers were used as a smoking reference group for the change in leucocyte blood counts after smoking cessation. Continuing smokers and quitters had comparable age, smoking history, and sex distribution (table 2).

Seventy one smokers were randomised to receive nicotine substitution with nicotine chewing gum $2 \mathrm{mg}$ (Lundbeck, Copenhagen, Denmark) for 12 weeks after smoking cessation and were still abstinent after 26 weeks. The cumulated number of nicotine chewing gum pieces used during 12 weeks was analysed to investigate any relationship with changes in leucocyte blood counts at 12 weeks after smoking cessation in the 71 nicotine substituted ex-smokers still abstinent after 26 weeks.
Forced expiratory volume in one second $\left(\mathrm{FEV}_{1}\right)$ and forced vital capacity (FVC) were measured with a dry spirometer (Vitalograph Ltd, Buckingham, UK) before the start of the trial in all participants and after six months in 160 quitters and 138 smokers with smoking abstinence lasting less than six weeks after quitting (relapsers). The best of three reproducible measurements with less than $5 \%$ variation was recorded. Normal values for $\mathrm{FEV}_{1}$ and FVC were from the European Working Party on Standardisation of Lung Function Tests. ${ }^{34}$ Standardised residuals of $\mathrm{FEV}_{1}$ and FVC were used to evaluate lung function. ${ }^{35}$

The smoking history was recorded with respect to duration of smoking (years), kind of tobacco smoked (pipe tobacco, cigarettes, small cigars and cigars), and name of the brand smoked. Pipe and cigar tobacco was converted into corresponding numbers of cigarettes $(1 \mathrm{~g}$ of pipe tobacco $=1$ cigarette, 1 small cigar $=3$ cigarettes, and 1 cigar $=5$ cigarettes).

Daily cigarette consumption was the daily consumption of tobacco converted into cigarettes. Pack years of consumption was defined for all smokers as duration of smoking multiplied by the number of cigarettes smoked per day and divided by 20 .

Tobacco abstinence was controlled by measuring the concentration of carbon monoxide (CO) in expired air (Ecolyzer CO Monitor, Hawthorne, New York, USA). Participants included in this study had to present a CO concentration in expired air of $\leqslant 2 \mathrm{ppm}$ at nine and 10 consecutive visits during 26 and 52 weeks, respectively, to maintain status as ex-smokers after 26 and 52 weeks, respectively. Failure to meet this demand caused exclusion from the study. No reruns were allowed.

Total leucocyte blood counts were measured with a Coulter counter S (Coulter Electronics, Hialeah, Florida, USA) and leucocyte differential blood counts were determined by counting 200 cells in a smear stained with MayGrunewald-Giemsa solution. Total neutrophil, lymphocyte, and basophil blood counts were calculated by multiplying the respective leucocyte differential blood counts by the total leucocyte blood counts.

All participants gave their informed concent to participate in the study which had the approval of the scientific ethics committee of Aarhus county.

\section{DATA ANALYSIS}

The BMDP statistical software package ${ }^{36}$ was employed in all calculations. Comparisons of demographic details between groups was performed with Pearson's $\chi^{2}$ and Student's $t$ test. The Student's $t$ test was used for comparisons of group means and the paired $t$ test, along with tests for repeated measures, was used to evaluate variations in the various leucocyte counts after smoking cessation. Bivariate and multivariate regression analyses were employed to evaluate relations between lung funtion and leucocyte blood counts before and after smoking cessation, and the relation between nicotine 
Table 3 Number of participants grouped according to smoking status and time

\begin{tabular}{lccc}
\hline & Smokers & Ex-smokers & Non-smokers \\
\hline Before quitting smoking & 298 & 0 & 136 \\
Cigarette smokers & 237 & - & - \\
Never ceased smoking & 30 & - & - \\
26 weeks after quitting day & 138 & 160 & 136 \\
52 weeks after quitting day & - & 92 & \\
\hline
\end{tabular}

Table 4 Total leucocyte, neutrophil, and lymphocyte blood counts at baseline per $\mu l$ in 237 cigarette smokers according to pack years and daily cigarette consumption

\begin{tabular}{lllll}
\hline & No. & Total leucocytes & Neutrophils & Lymphocytes \\
\hline $\begin{array}{l}\text { Pack years consumption } \dagger \\
\quad \leqslant 20\end{array}$ & 100 & $7.4(7.0 \text { to } 7.8)^{\star}$ & $4.3(4.0 \text { to } 4.6)^{\star \star}$ & $2.4(2.2 \text { to } 2.5)^{\star}$ \\
$\begin{array}{l}\text { Pack years consumption } \dagger \\
\quad>20\end{array}$ & 137 & $8.1(7.8$ to 8.4$)$ & $4.8(4.6$ to 5.1$)$ & $2.6(2.5$ to 2.7$)$ \\
$\begin{array}{l}\text { Daily cigarette } \\
\quad \text { consumption } \dagger \leqslant 20\end{array}$ & 119 & $7.6(7.3 \text { to } 7.9)^{\star}$ & $4.5(4.2 \text { to } 4.7)^{\star}$ & $2.3(2.1 \text { to } 2.5)^{\star}$ \\
$\begin{array}{l}\text { Daily cigarette } \\
\text { consumption } \dagger>20\end{array}$ & 179 & $8.5(8.0$ to 9.2$)$ & $5.3(4.8$ to 5.9$)$ & $2.5(2.4$ to 2.7$)$ \\
\hline
\end{tabular}

Values are given as geometric means ( $95 \%$ confidence limits).

${ }^{\star} \mathrm{p}<0.05 ;{ }^{\star \star} 0.05<\mathrm{p}<0.1$

†See text for definition.

Table 5 Relations between leucocyte blood counts and the decrease in FEV during six months (DFEV) in 138 relapsers

\begin{tabular}{lllll}
\hline Independent variable & Intercept & $\begin{array}{l}\text { Regression } \\
\text { coefficient (SE) }\end{array}$ & $r^{2}$ & $p$ \\
\hline Total leucocyte blood count & -27 & $3.9(0.6)$ & 0.26 & $<0.0001$ \\
Pack years consumption & -20 & $0.03(0.07)$ & 0.01 & NS \\
Total neutrophil blood count & & $5.1(0.7)$ & 0.31 & $<0.0001$ \\
Pack years consumption & 0.08 & $0.003(0.06)$ & 0.01 & NS \\
Total lymphocyte blood count & & $2.1(1.5)$ & 0.02 & NS \\
Pack years consumption & & $0.02(0.08)$ & 0.01 & NS \\
\hline
\end{tabular}

Multivariate regression analyses with DFEV as the dependent variable and independent variables as indicated.

$r^{2}=$ square of the correlation coefficient; $\mathrm{SE}=1$ standard error.

chewing gum consumption and decrease in leucocyte blood counts after smoking cessation.

The distributions of the leucocyte counts were not normal. To obtain a normal distribution natural logarithmic transformation was employed in the analyses. In the text geometric means and 95\% confidence limits (CI) are given by employing antilog to the means and to the $95 \%$ CI derived by analyses of the logarithmic transformed leucocyte counts. $p$ values of less than $5 \%$ were considered significant and $p$ values of $5-10 \%$ were considered to represent a trend.

\section{Results}

PARTICIPANT GROUPING

Participants were grouped into smokers, cigarette smokers, ex-smokers (quitters) at 26 and 52 weeks after smoking cessation, continuing smokers, relapsers at 26 weeks after smoking cessation, and non-smokers. The grouping of participants is given according to smoking status and time in table 3.

LEUCOCYTE BLOOD COUNTS IN SMOKERS AND NON-SMOKERS

The geometric means ( $95 \% \mathrm{CI})$ of the total leucocyte, neutrophil, lymphocyte, and basophil blood counts in smokers and non-smokers are given in table 1 . All cell counts were higher in smokers than in non-smokers.
ASSOCIATION OF LEUCOCYTE COUNTS WITH

SMOKING HISTORY

There was no significant relation between pack years or daily cigarette consumption and any of the leucocyte blood counts in the total population. The geometric mean (95\% CI) of the total leucocyte, neutrophil, and lymphocyte blood counts for 237 cigarette smokers grouped according to consumption of $\leqslant 20$ or $>20$ pack years and daily cigarette consumption of $\leqslant 20$ or $>20$ are given in table 4 . All blood count indices except basophils were higher in smokers with high pack years or daily cigarette consumption than in those with a lower consumption. The basophil blood counts had no association with smoking history.

\section{LUNG FUNCTION AND LEUCOCYTE BLOOD} COUNTS

In linear regression analyses including cigarette smokers, pack years consumption explained $8 \%(\mathrm{p}<0.0001)$ and daily cigarette consumption explained $2 \%(\mathrm{p}<0.05)$ of the variation in $\mathrm{FEV}_{1}$ residuals. Total leucocyte blood counts in cigarette smokers correlated inversely with $\mathrm{FEV}_{1}$ residuals and explained $11 \%$ (p $<0.0001$ ) of the variation in $\mathrm{FEV}_{1}$ when combined with pack years consumption and $3 \%(\mathrm{p}<0.01)$ when considered independently of pack years and daily cigarette consumption. Further linear regression analyses showed an inverse correlation between total neutrophil blood counts and $\mathrm{FEV}_{1}$ residuals, and the neutrophil blood counts explained $11 \%$ (p $<0.0001$ ) of the variation in $\mathrm{FEV}_{1}$ residuals when considered in combination with pack years consumption and $3 \%(\mathrm{p}<0.05)$ of the variation when considered alone and independently of pack years and daily cigarette consumption. No significant relations were found between total lymphocyte or basophil blood counts and lung function.

The mean $(95 \% \mathrm{CI})$ decline in $\mathrm{FEV}_{1}$ (DFEV) in 138 relapsers during six months was 7 (3 to 9) $\mathrm{ml}$. Multivariate linear regression analyses showed that the total leucocyte blood count and the total neutrophil blood count was related to DFEV when considered independently of pack years consumption (table 5). The total neutrophil blood count independent of pack years consumption explained $31 \%$ of the variation in DFEV (table 5). We found no relation between baseline total lymphocyte blood counts and decrease in $\mathrm{FEV}_{1}$ in relapsers during the six months of observation.

\section{LEUCOCYTE BLOOD COUNTS AFTER SMOKING} CESSATION

Repeated measure variance analyses showed a decrease in total leucocyte $(\mathrm{p}<0.01)$, neutrophil $(\mathrm{p}<0.05)$, and lymphocyte blood counts $(\mathrm{p}<0.001)$ during the 26 weeks after cessation of smoking in 160 quitters (fig 1). No significant changes were noted in the leucocyte counts in 30 subjects who continued to smoke during the same time span. The changes in the leucocyte counts after quitting were independent of smoking history and baseline $\mathrm{FEV}_{1}$ residuals. 


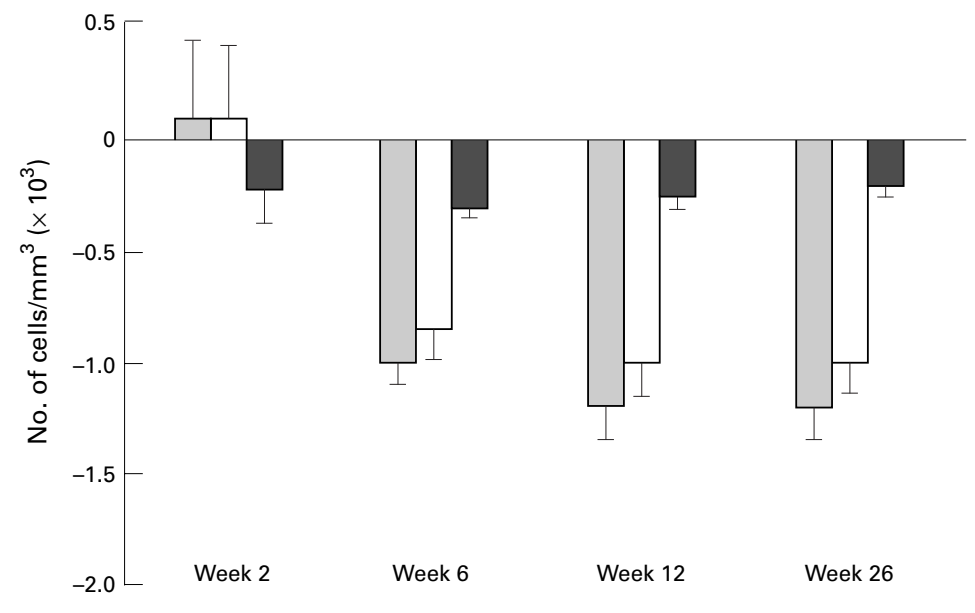

Figure 1 Mean (SE) difference in total leucocyte (light shaded bars), total neutrophil (white bars), and total lymphocyte blood counts (dark shaded bars) from baseline at weeks $2,6,12$, and 26 after smoking cessation in 160 ex-smokers. Total blood leucocytes ( $p$ $<0.01)$, neutrophils $(p<0.05)$, and lymphocytes $(p<0.001)$ decreased from baseline during the 26 weeks.

Table 6 Relation between the cumulated number of $2 \mathrm{mg}$ pieces of nicotine chewing gum used in 71 quitters who had received nicotine chewing gum substitution for 12 weeks and were still abstinent after 26 weeks and the decrease in leucocyte blood counts at 12 weeks after smoking cessation

\begin{tabular}{lllll}
\hline Dependent variable & Intercept & $\begin{array}{l}\text { Regression } \\
\text { coefficient (SE) }\end{array}$ & $r^{2}$ & $p$ \\
\hline Total leucocyte blood count & 2.1 & $-0.1(0.05)$ & 0.07 & $<0.05$ \\
Total neutrophil blood count & 1.6 & $-0.05(0.05)$ & 0.02 & NS \\
Total lymphocyte blood count & 0.6 & $-0.05(0.02)$ & 0.07 & $<0.05$ \\
\hline
\end{tabular}

Bivariate regression analyses with the cumulated number of pieces of chewing gum was the independent variable. $\mathrm{SE}=$ one standard error; $r^{2}=$ square of the correlation coefficient.

INFLUENCE OF NICOTINE CHEWING GUM ON THE CHANGE IN LEUCOCYTE NUMBERS AFTER SMOKING CESSATION

Seventy one participants had received nicotine chewing gum ( $2 \mathrm{mg}$ for 12 weeks after the cessation of smoking) and were still abstinent after 26 weeks. Linear regression analyses including this group showed an inverse relationship between the cumulated number of nicotine chewing gum pieces used during the 12 weeks and the decrease in the total leucocyte and lymphocyte blood count at 12 weeks after smoking cessation (table 6). There was no relation between the cumulated number of nicotine chewing gum pieces used and the decrease in neutrophils.

\section{LEUCOCYTE COUNTS AFTER ONE YEAR OF} ABSTINENCE

The geometric mean (95\% CI) total leucocyte, neutrophil, and lymphocyte blood counts at one year after smoking cessation in ex-smokers and in non-smokers are given in table 7 . To avoid an influence on leucocyte blood counts of nicotine chewing gum, analyses were per-

Table 7 Total leucocyte, neutrophil, and lymphocyte blood counts per $\mu$ in ex-smokers without any nicotine substitution and non-smokers after one year of smoking abstinence

\begin{tabular}{lll}
\hline & Ex-smokers & Non-smokers \\
\hline No. & 56 & 136 \\
Total leucocytes & $6.1(5.6$ to 6.5$)$ & $5.8(5.6$ to 6.0$)$ \\
Total neutrophils & $3.2(3.1$ to 3.6$)$ & $3.2(3.0$ to 3.3$)$ \\
Total lymphocytes & $2.3(2.1$ to 2.5$)$ & $2.0(1.9 \text { to } 2.1)^{\star}$ \\
\hline
\end{tabular}

Values are geometric means ( $95 \%$ confidence limits). ${ }^{\star} \mathrm{p}<0.05$. formed in ex-smokers without any nicotine substitution $(n=56)$. Total lymphocyte blood counts were still raised in ex-smokers compared with non-smokers one year after giving up smoking.

\section{Discussion}

This study was undertaken to search for relations between leucocyte counts, smoking, and lung function, and to look for a possible influence of nicotine substitution on leucocyte numbers.

The study showed increased numbers of total leucocytes, neutrophils, lymphocytes, and basophils in the blood of smokers compared with non-smokers. A weak negative association was found between blood neutrophil counts and lung function, a direct relationship between cigarette consumption and leucocyte blood counts, an inverse relationship between the cumulated number of nicotine chewing gum pieces used and the decrease in blood lymphocyte counts in ex-smokers 12 weeks after smoking cessation, and a persistent increase in lymphocytes in the blood one year after smoking cessation.

The numbers of non-smokers and exsmokers were rather small and this probably limited our ability to show a relation between some of the variables. The concentration of nicotine in the blood of the nicotine substituted quitters was not measured and this would have given more conclusive results regarding the influence of nicotine on the leucocyte blood counts.

Leucocyte counts estimated on a Coulter cell counter have a variability of $2 \%{ }^{37}$ and are dependent on race, sex, parity, and use of oral contraceptives. ${ }^{38}$ We confirmed the previously reported increase in total leucocyte blood counts and the size of the increase in smokers compared with non-smokers ${ }^{6-15}$ and the negative relation between the total leucocyte blood count and lung function in smokers. ${ }^{15-19}$ The total leucocyte blood counts independently accounted for about 3\% of the variation of $\mathrm{FEV}_{1}$ residuals and this effect of leucocytes on lung function makes this figure unsuitable for predicting accelerated loss of lung function in smokers. We confirmed a dose dependent relation beween cigarette consumption and the total leucocyte blood count, ${ }^{10-12}$ although we were not able to show any association between the magnitude of cigarette consumption and the decrease in the total leucocyte blood counts after cessation of smoking.

We confirmed previous reports 8101516 of a substantial increase in neutrophils in smokers compared with non-smokers. We also found that almost all of the variation in $\mathrm{FEV}_{1}$ residuals explained by the total leucocyte blood counts was due to neutrophils. This result is in accordance with the theory that the lung injuries observed in some smokers may be caused by cytotoxic products of neutrophils. ${ }^{15} 17{ }^{19}$ The higher decrease in $\mathrm{FEV}_{1}$ in those who relapsed with high baseline neutrophil blood counts during the six months of the study confirmed that the increased neutrophil blood counts in 
smokers may have a significant influence on the risk in smokers of developing obstructive lung disease.

We confirmed the increase in blood lymphocyte counts in smokers compared with non-smokers and the dose dependent relationship between cigarette consumption and lymphocyte counts. ${ }^{6101522}$ Smoking may cause substantial changes in the distribution of lymphocyte subtypes and impairment of lymphocyte function. ${ }^{21}{ }^{26}$ We found, however, no indication of an influence of these changes on lung function in smokers.

There have been reports of both an increase and a decrease in the number of basophils in the blood of smokers compared with non-smokers, ${ }^{27}{ }^{28}$ probably because of the large variability in numbers.

Participants in this study had no diseases such as airway infections ${ }^{38}{ }^{39}$ that might have influenced the blood leucocyte numbers, and prospectively showing a decrease in the counts of the blood leucocytes immediately after the cessation of smoking, confirmed the increased leucocyte counts in smokers.

The inverse relationship in regression analyses between the number of pieces of nicotine chewing gum used during the 12 weeks and the decrease in lymphocyte blood count in exsmokers at 12 weeks after smoking cessation was a strong indication of the stimulating effect of nicotine on lymphocytes. Misclassification of participants with respect to smoking status could have influenced this result. Only quitters with a concentration of carbon monoxide in expired air of $\leqslant 2 \mathrm{ppm}$ in nine consecutive tests over 26 weeks were classified as ex-smokers and included in these analyses. This implies a very low risk of misclassification of ex-smokers at 26 weeks after quitting. The mechanism by which nicotine influences lymphocyte blood counts is not known.

We were not able to show any relation between the decrease in the leucocyte blood counts and lung function, possibly because of a large variability in the counting methods. We confirmed a persistent increase in the total blood leucocyte count ${ }^{12}{ }^{12}$ but, in contrast to earlier reports, the increase was caused by a persistent elevation of lymphocyte numbers. We have no immediate explanation for this discrepancy, but it may be due to the influence of confounding factors in cross sectional studies.

The fast decline in leucocyte numbers was in accordance with the short lifetime of 1-4 days of neutrophils and some lymphocyte subpopulations. ${ }^{40}$

This study showed a clear dose-response relationship between smoking and leucocyte numbers and a significant but small independent negative association between lung function and neutrophil numbers. The inverse relationship between the cumulated number of pieces of nicotine chewing gum used and the decrease in the lymphocyte count after smoking cessation suggested a direct influence of nicotine on numbers of lymphocytes.
1 Dockery DW, Speizer FE, Ferris BG Jr, et al. Cumulative and reversible effects of lifetime smoking on simple tests of lung function in adults. Am Rev Respir Dis 1988;137:286-92.

2 Beck GJ, Doyle CA, Schacter EN. Smoking and lung funcion. Am Rev Respir Dis 1981;123:149-55.

3 Anderson DO, Ferris BG Jr. Role of tobacco smoking in the causation of chronic respiratory disease. $N$ Engl f Med 1962;267:787-94

4 Aurbach O, Hammond EC, Garfinkel L, et al. Relation of smoking and age to emphysema. Whole-lung section study. N Engl f Med 1972;286:853-7.

5 Fletcher C, Peto R, Tinker C, et al. The natural history of chronic bronchitis and emphysema. London: Oxford University Press, 1976.

6 Corre F, Lellouch J, Schwartz D. Smoking and leucocyte counts. Results of an epidemiological survey. Lancet 1971: ii:632-4.

7 Friedman GD, Siegelaub AB, Seltzer CC, et al. Smoking habits and the leucocyte count. Arch Environ Health 1973; 26:137-43.

8 Chan-Yeung M, Ferreira P, Frolich J, et al. The effects of age, smoking, and alcohol on routine laboratory tests. $A m \mathcal{F}$ Clin Pathol 1981;75:320-6.

9 Vanuxem, Sampol J, Weiller PJ, et al. Influence du tabagisme chronique sur les leucocytes. Respiration 1984; 46:258-64.

10 Noble CN, Penny BB. Comparison of leukocyte count and function in smoking and non-smoking young men. Infect Immun 1975;12:550-5.

11 Schwartz J, Weiss S. Cigarette smoking and peripheral blood leukocyte differentials. Ann Epidemiol 1994;4:236-42.

12 Schwartz J, Weiss S. Host and environmental factors influencing the peripheral blood leucocyte count. Am $\mathcal{F}$ Epidemiol 1991;134:1402-9.

13 Petetti DB, Kipp H. The leukocyte count: associations with intensity of smoking and persistence of effect after quitting. intensity of smoking and persisten

14 Carel RS, Eviatar J. Factors affecting leucocyte counts in healthy adults. Preventive Med 1985; 14:607-19.

15 Gillum RF. Peripheral leucocyte count and pulmonary function in a national sample of women and men. Ann Epidemiol 1991;1:525-31.

16 Bridges RB, Wyatt RJ, Rehm SR. Effect of smoking on peripheral blood leukocytes and serum antiproteases. Eur $\mathcal{F}$ Respir Dis 1985;66:24-33.

17 Bridges RB, Wyatt RJ, Rehm SR. Effects of smoking on inflammatory mediators and their relationship to pulmonary dysfunction. Eur $\mathcal{F}$ Respir Dis 1986;69(Suppl 14):14552.

18 Chan-Yeung $M$, Abboud R, Buncio AD, et al. Peripheral leucocyte count and longitudinal decline in lung function. Thorax 1988:43:462-6.

19 Carel RS, Tockman MS, Baser M. Smoking, leukocyte count, and ventilatory lung function in working men. Chest 1988;93:1137-43.

20 Sparrow D, Glynn RJ, Cohen M, et al. The relationship of the peripheral leukocyte count and cigarette smoking to pulmonary function among adult men. Chest 1984;86:383-

21 Hughes DA, Haslam PL, Townsend PJ, et al. Numerical and functional alterations in circulatory lymphocytes in cigarette smokers. Clin Exp Immunol 1985;61:459-66.

22 Tollerud DJ, Brown LM, Blattner WA, et al. T cell subsets in healthy black smokers and nonsmokers. Am Rev Respir Dis 1991;144:612-6.

23 Jacob CV, Stelzer GT, Wallace JH. The influence of tobacco smoke on the immune response. The cellular basis of mmunosuppression by a water-soluble condensate of tobacco smoke. Immunology 1980;40:621-7.

24 Tollerud DJ, Clark JW, Brown LM, et al. The effects of cigarette smoking on $\mathrm{T}$ cell subsets. Am Rev Respir Dis 989;139:1446-51

25 Tollerud DJ, Clark JW, Brown LM, et al. Association of cigarette smoking with decreased numbers of circulating natural killer cells. Am Rev Respir Dis 1989;139:194-8.

26 Berntorp K, Ekman M, Berntorp E. Cigarette smoke impairment of human lymphocyte function by inhibition of transglutaminase. F Int Med 1989:226:73-9.

27 Taylor RG, Gross E, Joyce H, et al. Smoking, allergy, and the differential white blood cell count. Thorax 1985; 40:9-16.

28 Walter S. Blood basophil counts in smokers and nonsmokers. Indian f Med Res 1982;72:317-9.

29 Walter S, Nancy NR. Basopenia following cigarette smoking. Indian $\mathcal{f}$ Med Res 1980;72:422-5.

30 Niewoehner DE, Kleinerman J, Rice DB. Pathological changes in the peripheral airways of young cigarette smokers. N Engl f Med 1974;291:755-8.

31 Hunninghake GW, Gadek JE, Crystal R. Mechanism by which smoke attracts polymorphonuclear leucocytes to whe lung. Chest 1983;77:273-6.

32 Totti N, McCusker KT, Cambell EJ, et al. Nicotine is chemotactic for neutrophils and enhances neutrophil chemotactic for neutrophils and enhances neutrophil responsive 223 .

33 Taylor RG, Woodman G, Clarke SW. Plasma nicotine concentration and the white blood cell counts in smokers. Tho$\operatorname{rax} 1986 ; 41: 407-8$.

34 Quanjer P, ed. Standardized lung function testing: report of Working Party on Standardization of Lung Function Tests. Bull Eur Physiopathol Respir 1983;19(Suppl 5):45-51.

35 Miller MR, Pincock AC. Predicted values: how should we use them. Thorax 1985;43:283-7. 
36 Dixon WJ, ed. BMDP statistical software. Los Angeles: University of California Press, 1990.

37 Statland BE, Winkel P, Harris C, et al. Evaluation of biologic sources of variation of leucocyte counts and other haematologic quantities using very precise automated analyzers. Am f Clin Pathol 1977;69:48-54.

38 Neukirch F, Kaufmann F, Korobaeff M Common cold with cough on the day of examination: a factor that should be taken into account in epidemiological studies on lung func-


respiratory symptoms. Ann Epidemiol 1993;3:57-63.

40 Gallin IJ. Quantative and qualitative disorders of phagocytes. In: Isselbacher, Braunwald E, Wilson DJ, et al, eds. Thirteenth edition of Harrison's principles of internal medicine. International Edition. New York: Mcgraw-Hill Inc, 1994: 329-35. 